\title{
D.R. Sherrod, W.E. Scott, P.H. Stauffer (eds): A volcano rekindled: the renewed eruption of Mount St. Helens, 2004-2006
}

\author{
USGS Prof. Paper 1750, 2009. 856 pp, plus DVD with appended data and figures, \\ $\$ 50$ printed, downloadable for free
}

\author{
William I. Rose
}

Received: 14 December 2009 / Accepted: 5 January 2010 /Published online: 2 February 2010

(C) Springer-Verlag 2010

Viscous extrusion of lava domes involves crystal-rich silicic degassed magmas which may be hot but solid rock when extruded. It is a surprising and spectacular phenomenon which is still being scientifically elaborated by real observations. This new volume is a treasure for students and scientists interested in the behavior and hazards of volcanic domes. It combines 37 scientific papers by USGS scientists and colleagues from all over the world. The work in this volume celebrates group-based volcanology and builds on similar work done at Mount St. Helens (19801986), Unzen (1990-1995), and Soufriere Hills, Montserrat (1994 to present). Its focus is the 2004-2006 eruption of Mount St. Helens, a re-invigoration of a post-plinian dacite dome after 18 years of repose.

The volume features valuable direct observations of dacite dome activity, and a major value is the abundant and carefully crafted illustrations produced in color. No serious discussion of viscous magma extrusions and especially spines should be done without absorbing this volume. It is

Editorial responsibility G. Heiken

W. I. Rose $(\bowtie)$

Geological Engineering \& Sciences,

Michigan Technological University,

1400 Townsend Dr,

Houghton, MI 49931, USA

e-mail: raman@mtu.edu divided into sections which cover seismology (six papers), geological observations (six papers), geodesy and remote sensing (five papers), models and mechanics of eruptions (four papers), crisis management (two papers), volcanic gas emissions (three papers), and petrology (ten papers). The whole body of work is integrated, and each paper is well informed by others in the volume.

The combination of techniques used in this volume offer basic data that will be tested against theory for decades. The volume is significant because silicic dome activity is recurrent and represents many persistent volcanic hazards situations worldwide (e.g., Merapi, Santiaguito, Redoubt, Shieveluch, Colima). The use of "spiders" for getting GPS data in dangerous settings (LaHusen et al., chapter 16), the detailed pattern of growth of the dome (Vallance et al., chapter 9), the use of digital aerophotogrammetry (Schilling et al., chapter 8), and the petrological comparisons of the 2004-2006 magma with 1980-1986 (Pallister, Rutherford, Thornber and Blundy et al., chapters 30-33) were highlights for this reviewer, but the whole volume is strong.

The accompanying DVD has very valuable data and imagery in a convenient format. The layout and editing is thorough and high quality. The volume may be freely downloaded wholly or by section or chapter (http://pubs. usgs.gov/pp/1750/). A hardcopy may be purchased at a low price $(\$ 50)$ and represents a logical complementary book format that many specialists will want. 